\title{
EDITORIAL: PREVENTION OF NUCLEAR WAR AND DISASTER PREPAREDNESS
}

Peter Safar, M.D.

Pit tsburgh, PA, USA

The above contributions by Professors Chazov and Lown, the comments by Dr. Rebentisch, and the Resolutions by the WAEDM, the Red Cross and the WHO indicate that disaster medicine planning for a response to and civil defense protection in case of nuclear war is senseless, wasteful of resources (which are needed for current vital social programs worldwide), and also dangerous, by giving national leaders the impression that some individuals' medical protection in a nuclear war is possible. Most people, including some national leaders and military experts, believe that limited use of nuclear weapons would escalate to a global nuclear holocaust, and that any medical planning for nuclear war might encourage the irrational belief that nuclear was is winnable. Even if it were "winnable" the resulting death and torture of millions of innocent people and the damage of our planet's ecologic balance, make any consideration of the military use of nuclear explosions morally and medically unacceptable.

Small neutral countries without nuclear weapons, such as Switzerland and Austria, have been forced to consider the possibility of a major conventional war, chemical war or even "limited" nuclear war waging around them, and endangering their territories and their populations. This might include temporary exposure to heavy nuclear fallout, after the effects of blast, heat and acute radiation destroyed neighboring countries' territories.

An additional problem to consider is the black-out of communications and other functions of electronic devices, by the electromagnetic pulse generated by a nuclear explosion. Such a nuclear explosion above the atmosphere could paralyze communications of an entire continent without causing casualties directly. Experts of uninvolved countries agree that protection against the direct blast, heat and acute radiation effects of a nuclear bomb explosion is not possible, but they add that protection against radioactive fallout, chemical weapons, blast effects of conventional bombs and shells, and fires, for a major portion of their population, is feasible.

The superpowers' past military and civil defense posture called for the planning of horizontal evacuation and the building of shelters in the case of nuclear fallout in their own territories. We were told that these plans have been abandoned by both superpowers. In the USA, for example, the Federal Emergency Management Agency (FEMA), a nonmedical organization, is, in cooperation with the Department of Health and Human Services and the Department of Defense, in the process of planning a National Disaster Medical System (NDMS) (see papers by Drs. J.C. Bisgard and M. Silverstein in this number of the Journal). This planning is meant for disasters which cannot be handled by regions or states, e.g., earthquakes, floods, or a nuclear plant accident in the USA. Even the scenarios of conventional wars anywhere in the world are being considered. Planning a NDMS for all-out nuclear war, however, is not considered feasible or desirable.

As an example of an intermediate stand on this issue, we have published above about the Swiss Civil Defense System. This middle road taken by wealthy neutral countries like Switzerland, however, is not primarily meant for nuclear war. Such countries' cynicism about the peaceful intentions of powers surrounding them is understandable from the lessons learned in two World Wars, when a strong military and civil defense posture helped Switzerland keep the war away from its territories.

The nuclear war orientation by the Swiss Federal Office of Civil Defense Bern, Switzerland 3003) has been stirred by the American film "The Day After." A commentary by the Swiss Office on February 16, 1984 read as follows: "The film is thoughtprovoking, and that is good. The scenario of Kansas City and Lawrence should not be blindly transferred to Switzerland. In these American cities there were no supplies and stockpiles, and no warning of fallout... The preparations Switzerland has made could ameliorate the sequelae of such a catastrophe... The civil defense law of March 23, 1962, has been implemented to the extent that there exist, at present (1984), modern artificially ventilated shelters for $80 \%$ of the population. These shelter places give relative protection against the effects of all types of weapons...In a future war in Europe, should it occur, the use of nuclear weapons cannot be 
totally ruled out. The results would be devastating. The resulting suffering, however, might be ameliorated by appropriate, timely civil defense measures. An absolute protection of course is impossible."

A similar response to the American film "The Day After" has been written by Professor Dr. Herbert Vetter of the University of Vienna (Landesgerichtstrasse 18, Vienna A 1010, Austria) in Zivilschutz (Swiss Federal Office of Civil Defense, Bern, Switzerland 3003, June 1984): "Sequelae of an unlimited nuclear war would be so horrendous that even an excellent film like The Day After cannot adequately illustrate the horrors. Effective protection against these effects would not be possible. Idealism must not lead to overlooking or denying clearly recognizable realities. Among these realities is the fact that not every limited nuclear war must inevitably escalate into an unlimited one. Neither one of the superpowers wants to have its territory included in such a battle field. They will make every effort to limit the Armageddon to other countries... If they succeed in that, it would be possible for Austria to remain outside the direct effects of nuclear weapons used on the battlefield of a conventional war. These countries, however, would have part of their territories contaminated by the resulting fallout. To protect the population against such fallout effects is therefore urgently necessary. To deny the need for such preparation, perhaps with reasoning that it would be senseless, would equal collective suicide."

Disaster medicine leaders who are involved in national disaster medical systems (NDMS) planning, should draw their own conclusions from the information provided above. This writer has concluded: (1) Countries threatened by conventional war may have reason to follow the Swiss example. (2) Effective civil defense protection against an all-out nuclear war is technologically not possible for suspected target areas.

People outside target areas who might survive because of shelters, will not find a world worth living in. This makes civil defense preparedness for nuclear war in any country debatable and not a high priority.

The following personal views and questions are on preventing disasters through world peace. Views differ among health professionals on where medical concerns end and political activism begins.

Efforts at resuscitating individuals become seemingly senseless when leaders consider to destroy entire civilizations (for "national defense" and "world power"). Is the health professional's concern limited to individual human beings or must it include humanity at large? The educational efforts of the International Physicians for the Prevention of Nuclear War (IPPNW) have included protection of our species and planet earth among physicians' concerns. Mutual verifiable freeze, reduction and perhaps elimination of nuclear arms would reduce psychologic depression particularly among the young, free large budgets for badly needed social programs and medical research, and reduce the chance of a nuclear war by accident - - all legitimate concerns of the medical profession. This approach, however, treats the symptoms not the causes of the disease. After total nuclear disarmament, nuclear weapons could be rapidly reproduced during a conventional war. Moreover, the use of biologic and chemical weapons and of conventional weapons to destroy entire cities, is also genocide, which the medical profession should help prevent. Thus, the causes of conventional wars need to be treated -- such as poverty, unemployment, diseases, natural disasters, lack of education, economic exploitation, oppression, lack of hope, fanaticism in nations and religions, craving of wealth and natural resources, and the rise of psychotic, paranoid, belligerent, noncommunicating and power-hungry leaders.

Health professionals worldwide can help prevent any war using their teaching, reasoning, arbitrating and clout. Is non-involvement on preventing wars compatible with the oathes of Hippocrates and Geneva? For preventive resuscitation of humanity and its planet, we must substitute humanism for imperialism. If this is "political," then political activism has become a public health method.

Achieving and maintaining world peace requires "an entirely new way of thinking" (quoting Albert Einstein) and multifaceted approaches. These include peaceful resolution of international disputes; peaceful competition of systems; East-West travel, trade, communication at all levels, and cooperative projects; and a new world law with justice for all. To prevent the ultimate disaster, war and peace decisions must not be left to "experts," who have failed to prevent wars throughout history, but are legitimate concerns of the brotherhood of man, including health professionals devoted to disaster medicine. 